\title{
ANALISIS PELAKSANAAN PROGRAM STBM PILAR PERTAMA STOP BUANG AIR BESAR SEMBARANGAN DI DESA AMPELU KABUPATEN BATANGHARI
}

\author{
Entianopa $^{1}$, Rara Marisdayana ${ }^{2}$, Lili Andriani ${ }^{3}$, Vera Hendriani ${ }^{4}$ \\ Program Study of Public Health STIKES Harapan Ibu, Jambi \\ Email : en_thia@yahoo.co.id
}

\begin{abstract}
ABSTRAK
Desa Ampelu merupakan salah satu desa yang telah melaksanakan program STBM. Masalah yang dihadapi masyarakat yaitu penyediaan air bersih dan sanitasi. Sebagian masyarakat masih menggunakan jamban cemplung yang berada di pinggir sungai Batang Hari dan Buang Air Besar Sembarangan. Pelaksanaan program sudah berjalan satu tahun namun berdasarkan data Dinas Kesehatan pada tahun 2014-2016 belum mengalami peningkatan pencapaian program STBM Stop BABS.Tujuan penelitian adalah untuk menganalisis pelaksanaa program STBM pilar pertama stop BABS. Penelitian ini merupakan penelitian kualitatif bersifat deskriptif mendapatkan informasi secara akurat dan mendalam dari 9 sumber yang dianggap kompeten dengan menggunakan melalui wawancara mendalam, telaah dokumen dan observasi sehingga dapat diperoleh informasi tentang pelaksanaan program STBM. Penelitian ini dilakuan di Desa Ampelu. Hasil penelitian ini menunjukan pada pelaksanaan program STBM di Desa Ampelu terdapat beberapa faktor yang menghambat pelaksanaan program STBM Pilar pertama Stop BABS. Faktor tersebut yaitu buruknya akses jalan menuju desa, letak geografis, tingkat pendapatan masyarakat, tingkat pendidikan, pengetahuan dan perilaku masyarakat tentang buang air besar sembarangan. Pelaksanaan Program Sanitasi Total Berbasis Masyarakat di Desa Ampelu, wilayah kerja Puskesmas Muara Tembesi sudah berjalan namun belum optimal. Masih banyak kekurangan seperti misalnya tenaga kesehatan yang berkompeten dibidangnya, sarana serta prasarana.
\end{abstract}

Kata Kunci : Pelaksanaan Program STBM, Stop BABS

\begin{abstract}
Ampelu village is one of the villages where STBM (Community-Based Total Sanitation Program) program has been implemented. The problem faced by the community is the provision of clean water and sanitation, some people still use toilets on the edge of the river Batang Hari and defecate indiscriminately. Although the program has been implemented forone year, based on data from the Department of Health in 2014-2016, the achievement of STBM Stop BABS program has not been increased. This research is a descriptive qualitative research by obtaining accurate and in-depth information from 9 key informants by using in-depth interviews, document review in regards to the implementation of STBM program. This research was conducted in Ampelu Village. The results of this study indicate that there are several factors that impede the implementation of the first STBM Pillar Stop BABS program in Ampelu village. The factor is poor road access to the village, its human resources, geographical location, the level of community income, the level of knowledge and behavioral education the community about defecate and in the river.The implementation of the STBM Program in Ampelu Village, within the catchement area of Muara Tembesi Health Center has been implemented but not yet optimal, there are still many deficiencies such as Health Manpower, Facilities and Infrastructure, so that there are still many people who defecate in rivers and do not have latrines.
\end{abstract}

Keywords: Implementation of STBM Program, Stop BABS

\section{PENDAHULUAN}

Pembangunan kesehatan adalah penyelenggaraan upaya kesehatan oleh bangsa Indonesia, untuk meningkatkan kesadaran, kemauan dan kemampuan hidup sehat bagi setiap orang, agar dapat terwujud derajat kesehatan masyarakat yang setinggi-tingginya (Kepmenkes RI, 2011).

Tantangan yang dihadapi Indonesia terkait pembangunan kesehatan, khususnya bidang higiene dan sanitasi masih sangat besar. Untuk itu perlu dilakukan intervensi terpadu melalui pendekatan sanitasi total. Pemerintah merubah pendekatan pembangunan sanitasi nasional dari pendekatan sektoral -dengan penyediaan subsidi perangkat keras- yang selama ini tidak memberi daya ungkit terjadinya perubahan perilaku higienis dan peningkatan akses sanitasi, menjadi pendekatan sanitasi total berbasis masyarakat yang menekankan pada 5 (lima) dianataranya Stop BABS, pengelolaan limbah cair rumah tangga yang 
aman, pengelolaan air minum dan pengelolaan makanan rumah tangga, cuci tangan pakai sabun, pengelolaan sampah dengan benar.(Kepmenkes RI, 2014).

Sanitasi dan perilaku kebersihan yang buruk serta air minum yang tidak sehat menjadi pangkal soal penyakit terutama diare. Diare berkontribusi terhadap 88\% kematian anak di seluruh dunia. Adapun bagi anak-anak yang bertahan hidup, diare berpengaruh terhadap serapan gizi, sehingga menghalangi anak-anak untuk dapat mencapai potensi maksimal mereka (Heston danWati, 2016).

Kondisi ini selanjutnya menimbulkan implikasi serius terhadap kualitas sumber daya manusia dan kempampuan prokduktif suatu bangsa dimasa yang akandatang. Di Indonesia, diare masih merupakan penyebab utama kematian dibawahlima tahun. Laporan Riskesdas 2007 menujukkan diare sebagai penyebab 31\% kematian anak usia antara 1 bulan hingga satu tahun, dan $25 \%$ kematian anak usia antara satu sampai empat tahun( Heston danWati, 2016).

Berlatar belakang masalah sanitasi yang dihadapi oleh bangsa Indonesia, Pemerintah Indonesia mengajak seluruh lapisan masyarakat untuk berpartisipasi secara aktif dalam program yang dicanangkan. Program pemerintah untuk mengatasi permasalahan sanitasi disini beranama CLTS (Community Lead Total Sanitation) yang di selenggarakan di 6 kabupaten di 6 propinsi di Indonesia, diantaranya Muaro Jambi, Jambi; Muaro Enim, Sumatera Selatan; Bogor, Jawa Barat; Lumajang, Jawa Timur; Sambas, Kalimantan Barat; dan Sumbawa, Nusa Tenggara Barat. Program CLTS kemudian berganti nama menjadi STBM (Sanitasi Total Berbasis Masyarakat) yang dituangkan dalam Keputusan Menteri Kesehatan nomor 852/MENKES/SK/IX/2008 tentang Strategi Nasional Sanitasi Total Berbasis Masyarakat(Nugraha Moh. Fajar 2015).

Dari 6 Provinsi yang terdaftar dalam program STBM yang dicanangkan pemerintah, Jambi merupakan salah satu provinsi yang termasuk kedalam program tersebut. Salah satu Kabupaten dalam rovinsi Jambi yaitu kabupaten Batang Hari yang telah menyelenggarakan program STBM, namun berdasarkan laporan Dinas Kesehatan Batang Hari diwilayah kerja Puskesmas Muara Tembesi yang telah melaksanakan program STBM yaitu Desa Ampelu.pada tahun 2015-2016 kurangnya pencapaian program STBM di Desa tersebut, hal ini dapat dilihat dari jumlah masyarakat yang masih Buang Air Besar Sembarangan (BABS). Berdasarkan laporan data Dinas Kesehatan Kabupaten Batang Hari tahun 2015-2016 jumlah KK di Desa Ampelu yang masih BABS sebanyak $30 \mathrm{KK}$ dari $123 \mathrm{KK}$ dan belum mengalami perubahan .

Berdasarkan survey awal yang dilaksanakan di Desa Ampelu, informasi yang diperoleh dari petugas kesehatan di wilayah kerja Puskesmas Muara Tembesi jumlah tenaga kesehatan yang menangani program tersebut hanya 1 orang dan 8 kader dari masyarakat.

Berdasarkan latar belakang dari masalah diatas maka peneliti ingin melakukan analisis masalah lebih lanjut dan melihat sejauh mana program ini berhasil, dengan melakukan penelitian tentang Analisis Pelaksanaan Program STBM Pilar Pertama Stop Buang Air Besar Sembarangan di Desa Ampelu Kabupaten Batang Hari Tahun 2015.

\section{METODE}

Penelitian ini bersifat deskriptif, menggunakan pendekatan kualitatif dimana penulis ingin mendapatkan informasi secara akurat dan mendalam dari sumber yang dianggap kompeten dengan menggunakan metode wawancara mendalam, telaah dokumen dan observasi lapangan sehingga dapat dilihat bagaimana gambaran dari proses pelaksanaan Program STBM yang berada di wilayah kerja Pusksesmas Muara Tembesi Kabupaten Batanghari Tahun 2015. Yang meliputi komponen input (tenaga, dana, dan sarana), komponen proses (perencanaan dan pelaksanaan), dan komponen output $0 \%$ (Stop BABS).

Cara memperoleh data dalam poenelitian ini adalah dengan cara wawancara mendalam, observasi dan telaah dokumen pada Kasi Program (1 orang), Kepala Puskesmas/Dokter (1 orang) Penanggung jawab Kesling (1 orang), Penanggung jawab Promkes Puskesmas (1 orang), Bidan desa (1 orang), Tokoh masyarakat (2 orang), Kader STBM (2 orang).

\section{HASIL DAN PEMBAHASAN}

Desa Ampelu merupakan salah satu desa yang terletak di Kabupaten Batang Hari, Provinsi Jambi. Merupakan salah satu desa yang mendapatkan program STBM dari dinas kesahatan.

\section{Tenaga}

Dari hasil wawancara mendalam diketahui bahwa petugas Puskesmas yang melakukan Program STBM di desa Ampelu memiliki latar belakang pendidikan S1 Kesehatan Lingkungan. Tenaga tersebut sudah sesuai. Dari hasil wawancara mendalam juga diketahui bahwa kader pelaksana STBM di desa Ampelu dengan latar belakang pendidikan SLTA

Masa kerja juga memepengaruhi keterampilan petugas kesehatan dalam pelaksanaan program STBM tersebut. Dengan masa kerja yang cukup 
lama, diharapkan petugas kesehatan terampil dan mampu dalam pelaksanan tugasnya. Tetapi dengan masa kerja yang pendek petugas sudah terampil dan mampu dalam pelaksanaan kegiatan, masa kerja petugas kesehatan, tokoh masyarakat dan kader dalam pelaksanaan program STBM di desa Ampelu sudah cukup. Menurut Sutiyono dkk (2014). Pelatihan merupakan kegiatan yang bertujuan untuk meningkatkan keterampilan petugas dalam melaksanakan program STBM. Petugas kesehatan dan kader atau tenaga kesehatan masyarakat (TKM) program STBM sudah pernah mendapatkan pelatihan yang dilakukan di Dinas Kesehatan Kabupaten Batanghari, sesuai dengan informasi yang di dapatkan dari beberapa informan. .

Pelatihan Program STBM sangat perlu diberikan kepada petugas kesehatan dan kader STBM karena pelatihan dapat meningkatkan keterampilan dan kemampuan agar petugas dan kader dapat melaksanakan tugasnya dengan efektif sehingga memicu masyarakat untuk mengubah perilaku. Namun pelatihan STBM hanya dilakukan satu kali dalam satu bulan, sehingga petugas kurang memahami program tersebut.

Jumlah tenaga kesehatan juga mempengaruhi kelancaran program STBM. Jumlah tenaga Puskesmas yang ikut dalam pelaksanaan program STBM hanya petugas Kesling. Sedangkan petugas promkes dan bidan desa tidak dilibatkan dalam program. Sehingga untuk memicu dan mengajak masyarakat agar termotivasi atau berpartisipasi dalam pelaksanaan program STBM belum optimal.Bidan desa yang memberikan pelayanan kesehatan di desa Ampelu merupakan Bidan desa yang wilayah kerja nya di desa Ampelu mudo, desa Ampelu sendiri tidak memiliki Bidan desa yang bekerja dan memberikan pelayanan kesehatan tetap di desa Ampelu.

\section{Dana (Keters ediaan dan Pengelolaan)}

Dari hasil wawancara mendalam diketahui bahwa dana Pelaksanaan Program STBM berasal dari dinas kesehatan, APBN, BOK, DAK dan Swadaya Masyarakat seperti informasi yang disampaikan oleh beberapa informan dan untuk kecukupannya sudah cukup.

Suatu program akan berjalan atau berhasil bila ada dukungan dana yang cukup untuk pelaksanaan suatu program dengan demikian. Dana yang ada harus cukup dan jika dana tidak mencukupi maka harus mencari pemecahan masalah. Menurt peneliti seharusnya desa memiliki alokasi dana sendiri. Namun dana pelaksanaan program STBM lebih dominan berasal dari Dinas Kesehatan dan APBN sehingga untuk pelaksanaan program sering terbengkalai karena hanya mengandalkan dana yang tersedia saja.

Dana yang disediakan oleh Dinas Kesehatan dan APBN untuk pembangunan atau pelaksanaan program STBM memang sudah mencukupi namun dalam pelaksanaan atau pemanfaatan di desa terdapat kesenjangan antara pendapat dan fakta, karena tidak semua masyarakat dapat merasakan manfaat dari STBM tersebut.

\section{Sarana dan Prasarana}

Dari hasil wawancara mendalam dan observasi deketahui bahwa sarana untuk pelaksanaan program STBM di desa Ampelu sudah memadai karena alat dan bahan tesebut sudah disediakan langsung oleh Dinas Kesehatan Kabupaten Batanghari, untuk mempromosikan tentang kesehatan khususnya mengenai STBM dengan menggunakan leaflet, brosur dan penyuluhan.

Kendaraan operasional khususnya untuk sanitasi seperti yang disampaikan informan bahwa petugas kesehatan Puskesmas Muara Tembesi tidak memiliki kendaraan operasional khusus namun Puskesmas mempunyai kendaraan operasioanal yang bisa digunakan untuk petugas sebagai transportasi untuk melakukan kegiatan di desaMenurut sutiyono dkk (2014) Sarana dan prasarana merupakan peralatan yang digunakan untuk mendukung pelaksanaan kegiatan pelaksanaan program sanitasi total berbasis masyarakat. Sarana dan prasaran sangat penting dan mendukung untuk keberhasilan dan kelancaran suatu program khusunya program Sanitasi Total Berbasis Masyarakat untuk memicu kesadaran masyrakat agar tidak ada lagi masyarakat yang BABS.

Pemberian leaflet, pemasangan brosur dan pemutarn film atau video juga di anggap sangat penting di bagikan kepada masyarakat pada saat ada pertemuan seperti penyuluhan, Posyandu, PKK agar masyarakat sendiri menyadari bahwa pentingnya program STBM khususnya pilar pertama Stop BABS dapat meningkatkan derajat kesehatan masyarakat itu sendiri.

\section{Perencanaan}

Dari hasil wawancara mendalam diketahui bahwa petugas ikut serta dalam perencanaan pelaksanaan Program STBM dan petugas membuat perencanaan bentuk kegiatan awal sebelum melakukan kegiatan. Menurut peneliti kegiatan perencanaan sangat penting. Perencanaan meliputi kegiatan untuk menyusun usulan, mengajukan pendapat, dan menyusun kegiatan pelaksanaan, untuk menjelaskan apa saja rencana kegiatan yang 
akan di lakukan, sehingga dalam pelaksanaan tidak menyimpang. Pada perencanaan di harapkan semua pihak terkait dalam Program STBM Dinas Kesehatan, tokoh masyarakat, petugas kesehatan, bidan desa serta kader, agar dapat mengambil kebijakan, pengawasan, pemantauan dab siapa saja yang bertanggung jawab dalam pelaksanaan yang akan di jalankan.

\section{Pelaksanaan}

Dari hasil wawancara mendalam diketahuai bahwa pelaksanaan program STBM sudah terlaksana namun dalam pelaksanaan kegiatannya masih banyak faktor yang mengahambat misalnya kondisi jalan yang rusak, petugas tidak memiliki kendaraan operasional, fasilitas, dan sebagaian masyarakat yang tidak mau ikut iuran.

Pertama karena kondisi jalan yang rusak keadaan ini membuat desa sulit dijangkau, kedua pembagaian leaflet dan brosur hendaknya di edarkan kepada masyarakat pada saat ada penyuluhan dan pertemuan-pertemuan. Ketiga dengan menamabah tenaga kesehatan untuk meningkatkan kesedaran masyarakat untuk hidup bersih dan sehat. Keaktifan petugas juga berpengaruhi karena petugas kesehatan harusnya ikut memantau program tersebut berhasil atau terlaksana dengan baik. Keempat SDM sebagiannya masyrakat yang masih rendah tingkat pendidikan dan tingkat pendapat perkapita yang mempengaruhi, (Priatno.T, Zauhar, \& Hanafi, 2014 ) Menurut Conyers dan Hill (1984) sumberdaya manusia itu sangat diperlukan baik dari sisi kuantitas maupun kualitas. Dalam hal ini adalah SDM yang memiliki kinerja yang baik, memiliki motivasi yang tinggi serta memiliki etos kerja. Dari sisi kuantitas SDM sebaiknya memenuhi kriteria dan jumlahnya sesuai dengan proporsi dan beban kinerja yang diperlukan untuk di masing-masing daerah.

\section{Output}

Melalui wawancara mendalam output membahas tentang Stop BABS Program Sanitasi Total Berbasis Masyarakat, dimana berdasarkan hasil wawancara mendalam diketahui bahwa untuk pelaksanaan STBM belum mencapai target dimana masih banyak nya masyarakat yang BAB di sungai dan masyarakat yang tidak memiliki jamban.Kebiasaan masyarakat yang BABS pada umumnya yaitu masyarakat yang tempat tinggalnya di pnggir sungai Batang Hari sehingga masyarakat lebih memilih $\mathrm{BAB}$ di sungai dan tidak membuat jamban di rumah mereka sendiri.

Dengan meningkatkan peran serta masyarakat melalui penyuluhan diharapkan masyarakat terpicu untuk membuat jamban sendiri dan Stop Buang Air
Besar Sembarangan. Mengingat pada umumya masyarakat yang berada di pinggir sungai Batanghari buang air besarnya di sungai dan masih menggunakan air sungai untuk mandi.

\section{SIMPULAN}

Dari hasil analisa dan pembahasan paada penelitian ini dapat disimpulkan bahwa:

\section{Input}

Tenaga kesehatan Pelaksanaan Program STBM masih kurang yaitu hanya satu orang tenaga Kesling, tenaga Promkes dan Bidan desa tidak dilibatkan sehingga untuk pemicuan masih kurang. Latar belakang pendidikan tenaga Kesling sudah sesuai yaitu S1 kesling. Sumber dana untuk Pelaksanaan Program Sanitasi Total Berbasis Masyarakat berasal dari Dinas Kesehatan, APBN, BOK, DAK, dan swadaya masyarakat dan dana tersebut sudah cukup. Namun dana untuk pelaksanaan program yang dijalankan oleh desa belum cukup .Sarana dan Prasarana untuk pelakasanaan program STBM telah mencukupi namun tenaga kesehatan tidak memiliki kendaraan khusus sehingga dalam pelaksanaannya belum optimal.

\section{Proses}

Perencanaan Pelaksanaan Program Sanitasi Total Berbasis Masyarakat, petugas membuat perencanaan awal dan ikut serta dalam perencanaan tersebut. pelaksanaan program STBM sudah berjalan namun belum optimal sebab masih kurangnya tenaga kesehatan, sarana prasarana, kondisi jalan yang rusak, SDM, Ekonomi ,fasilitas, kebiasaan masyarakat yang masih $\mathrm{BAB}$ di sungai, sebagaian masyarakat yang tidak mau ikut iuran, timgkat pendidikan masyarakat, petugas kesehatan promkes dan bidan desa yang tidak dilibatkan dalam pelaksanaan.

\section{Output}

Pelaksanaan Program STBM Stop BABS di desa Ampelu Kabupaten Batanghari Tahun 2015 belum mencapai target karena masih banyaknya yang masih $\mathrm{BAB}$ di sungai dan tidak memiliki jamban.

\section{SARAN}

Dalam hal ini diharapkan Dinas Kesehatan dan Kepala Puskesmas dapat meningkatkan keterlibatan tenaga kesehatan yang ada di Puskesmas Muara Tembesi dan Bidan di desa untuk melaksanakan Program STBM Stop BABS. Diharapkan desa mempunyai alokasi dana sendiri untuk memenuhi kebutuhan dan pemanfaatan program STBM di Desa. Diharapkan Dinas Kesehatan dan Kepala Puskesmas dapat memenuhi kekurangan tenaga kesehatan, sarana dan 
prasarana. Dinas Kesehatan Kabupaten Batanghari dan Kepala Puskesmas Muara Tembesi dapat mengawasi dan memantau pelaksanaan program STBM yang dilaksanakan oleh tenaga kesehatan, kader dan tokoh masyarakat. Petugas Kesehatan dan kader STBM lebih meningkatkan lagi kegiatan Program STBM Stop BABS agar tidak ada lagi masyarakat yang $\mathrm{BAB}$ di sungai dan target mencapai $100 \%$

\section{DAFTAR PUSTAKA}

Permenkes RI, 2014. Nomor : 3 sanitasi Total Berbasis Masyarakat, Jakarta.

Kepmenkes RI, 2011. Pengelolaan Promosi Kesehatan, Peningkatan Perilaku Hidup Bersih Dan Sehat(PHBS). Jakarta

Priatno, teguh dkk.(2014). Faktor-faktor yang berpengaruh terhadap keberhasilan terhadap keberhasilan program Sanitasi Total Berbasis Masyarakat (STBM) dikota Tasikmalaya. Jurnal Kesehatan Komunitas Indonesia. Vol .10. No.2. 1038-1053.

Nugraha, Fajar Moh, 2015. Dampak Program Sanitasi Total Berbasis Masyarakat (STBM) pilar pertama didesa Gucialit Kecamatan Gucialit Kabupaten Lumajang. Kebijakan dan Manajemen Publik. Vol. 3 No.2. 44-53

Heston, Yudha Pracastino, Wati, Nur Alvira Pasca. 2016 Sanitasi dan Kesehatan Lingkungan; Pengukuran Dan Berkelanjutannya, Edisi pertama. Yogyakarta: Teknosain

Sutiyono dkk. (2014). Analisis Pelaksanaan Program Sanitasi Total Berbasis Masyarakat (STBM) Sebagai Strategi Peningkatan Perilaku Hidup Bersih dan Sehat (PPHBS) Masyarakat oleh Petugas Puskesmas Kabupaten Grobogan. Manajemen Kesehatan Indonesia. Vol . 02. No 1 